\title{
Influences of Mineral Admixture On the Compressive strength of Magnesium Oxysulphate Cement
}

\author{
CHEN Wenhai ${ }^{1, a}$,WU Chengyou ${ }^{1,2, b}$, YU Hongfa ${ }^{3}$, ZHENG Shuhai $^{1, \mathrm{c}}$ \\ ,CHEN Fangyu ${ }^{1, \mathrm{~d}}$, ZUO Huimin ${ }^{1, \mathrm{e}}$ \\ ( ${ }^{1}$ School of Civil Qinghai University, Xining China,810016 \\ ${ }^{2}$ Qinghai institute of Salt Lake,Chines Academy of Sciences, Xining,China, 810008 \\ ${ }^{3}$ Department of Civil Engineering ,Nanjing University of Aeronautics ,Nanjing,China 210016) \\ a810159416@qq.com, ${ }^{\mathrm{b}}$ wuchengyou86@163.com, \\ c79828740@qq.com, $540888538 @ q q . c o m,{ }^{e}$ 2273041915@qq.com
}

\begin{abstract}
Keywords: Magnesium oxysulphate cement;Mineral admixture; Compressive strength; Magnesium Oxide; Phase composition
\end{abstract}

Abstract. In this paper, influences of mineral admixtures (fly ash, slag and silica fume) on the compressive strength of magnesium oxysulphate cement have been studied. Results demonstrate that effects on compressive strength of magnesium oxysulphate cement by adding fly ash is related with the initial a- $\mathrm{MgO} / \mathrm{MgSO}_{4}$. The strength of cement increased by dosage of fly ash increases at low a-MgO/MgSO 4 . The addition of fly ash can significantly reduce the strengths of cement with constant water-cement ratio(w/c). Although adding slag is disadvantageous to the early strength of magnesium oxysulphate cement, it has little influence on the later strength. The early strength of the magnesium oxysulphate cement decreases at first and then increases with the increasing dosage of silica fume, and the later strength increases obviously.

\section{Introduction}

Mgnesium oxysulfate (MOS) cement is a kind of magnesia cementitious materials prepared by active magnesia (a-MgO) and magnesium sulfate solution. Due to outstanding properties of light weight ,good fire-resistance, good protections to steel and low thermal conductivity ${ }^{[1,2]}$, it can be widely used in producing light insulation board ,electrical insulating materials and fire-proofing materials. However, its high cost and some lower mechanical strengths have restricted the large-scale practical application,then in the magnesium cement production process, adding a certain amount of mineral admixture (such as fly ash, silica fume, slag) ${ }^{[3]}$, can improve the performance of magnesium cement, such as strength, water-resistance, and various industrial by-products can be well used,which can save resources and reduce cost. By adding fly ash and slag, Yu ${ }^{[4]}$ prepared $\mathrm{MgO}-\mathrm{SF}-\mathrm{FA}-\mathrm{MgCl}_{2}-\mathrm{H}_{2} \mathrm{O}$ cementitious materials, which greatly improved the mechanical properties and water- resistance of magnesium oxychloride cement . Some studies ${ }^{[5]}$ found that the mixing of fly ash and silica fume could produce different drying shrinkage of magnesium oxychloride cement.The fly ash was also found to be involved in the reaction of cement concrete of magnesium oxychloride, cementitious materials produced from the process made the paste structure more dense, and the water-resistance of the concrete was highly improved. Long-term researches show that adding mineral admixture can not only decelerate the forming speed of early reaction product and hydration heat, effectively improve the cracking and deformation of magnesium oxychloride cement, but also improve the water- resistance ability.

In view of compressive strength is one of the most important properties of cement, this paper will mainly study the influences of different mineral admixtures on the compressive strength of the magnesium oxysulphate cement, respectively. 


\section{Materials and experimental procedures}

\section{Raw materials}

The magnesia used in this study is light-burnt magnesia (LBM) obtained by calcining magnesite from Liaoning, China at $750{ }^{\circ} \mathrm{C}$, and the chemical composition of the LBM is listed in Table 1. In this $\mathrm{LBM}$, the content of a-MgO is necessary to be tested since only active $\mathrm{MgO}(\mathrm{a}-\mathrm{MgO})$ can hydrate and convert to any magnesium subsulfate in the magnesium sulfate solution .According to Dong' $\mathrm{s}^{[6]}$ report, the content of a-MgO in this study is tested with the standardized hydration method. The result shows only $58.50 \%$ of a-MgO consists in LBM. The calcined dolomite powder used in the study is provided from calcination of dolomite mineral from Inner Mongolia, China at $750^{\circ} \mathrm{C}$, and the chemical composition of the calcined dolomite powder is listed in Table 1. Magnesium sulfate $\left(\mathrm{MgSO}_{4} \cdot 7 \mathrm{H}_{2} \mathrm{O}\right)$ is analytically pure and purchased from Tianjin Hongyan Ltd., China.Fly ash, silica fume and slag are from Tianjin, Guizhou and Jiangsu respectively, with the chemical composition listed in Table 1.

Table 1 Chemical compositions of light-burnt magnesia powder ,calcined dolomite powder,fly ash slag and silica fume

\begin{tabular}{cccccc}
\hline & LBM & $\begin{array}{c}\text { calcined dolomite } \\
\text { powder }\end{array}$ & fly ash & slag & $\begin{array}{c}\text { silica } \\
\text { fume }\end{array}$ \\
\hline $\mathrm{MgO}$, wt.\% & 80.20 & 26.17 & 0.47 & 10.59 & 1.50 \\
\hline $\mathrm{CaO}$,wt.\% & 1.30 & 38.10 & 2.16 & 36.35 & 0.50 \\
\hline $\mathrm{SiO}_{2, \text { wt. } \%}$ & 6.07 & 1.54 & 52.37 & 33.48 & 92.00 \\
\hline $\mathrm{Fe}_{2} \mathrm{O}$,wt.\% & 0.41 & 3.11 & 4.12 & 1.400 & 2.00 \\
\hline $\mathrm{Al}_{2} \mathrm{O}_{3}$,wt.\% & 0.15 & 1.23 & 32.13 & 12.31 & 1.00 \\
\hline Others,wt.\% & 11.87 & 29.85 & 8.75 & 5.86 & 3.00 \\
\hline
\end{tabular}

Specimen preparation

In this experiment, the choices of molar ratios of a-MgO/MgSO $4(\mathrm{M})$ were 5,8 and 9 , and $\mathrm{H}_{2} \mathrm{O}$ $/ \mathrm{MgSO} 4(\mathrm{H})$ were from 14 to 24. To prepare neat MOS cement specimens, $\mathrm{MgSO}_{4} .7 \mathrm{H}_{2} \mathrm{O}$ was firstly dissolved into water to form a 25.wt\% MgSO4 solution, and the dosages added in the cement of fly ash ,slag and silica fume were from 0 to $40 \%$, secondly mix LBM ,mineral admixtures with MgSO4 solution to form MOS cement paste. The MOS cement paste was cast into $20 \times 20 \times 20 \mathrm{mmPVC}$ molds, sealed and cured at $20 \pm 3^{\circ} \mathrm{C}$ for about $24 \mathrm{~h}$ before demolding.

\section{Effect of fly ash on cement}

Effect of fly ash on strength

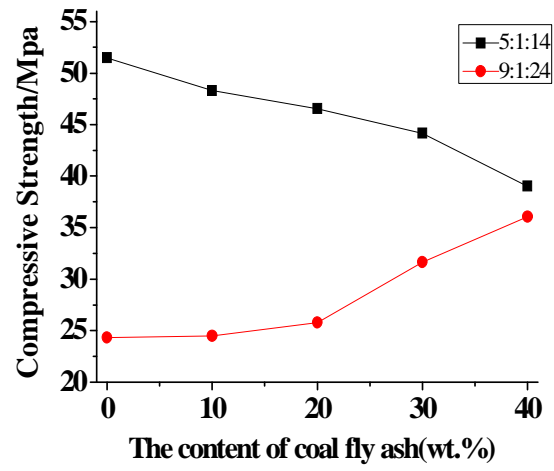

Fig. 1 Effects of dosage of coal fly ash on 28d compressive strength of magnesium oxysulfate cement with constant $\mathrm{H}$ 
Fig. 1 shows that when $M$ is small(eg.M=5)and $H$ is constant,28d compressive strength of magnesium oxysulfate cement decreases with the increasing dosage of fly ash . Moreover, it has opposite results when $\mathrm{M}$ is large (eg.M=9). This proves the effect of fly ash on the strength of magnesium oxysulfate cement is related to the ratio of raw materials.

The possible reason is (1)with the addition of fly ash, the reactant is dispersed and isolated, so the concentration of reactant is diluted ${ }^{[7]}$. Besides ,the content of active $\mathrm{MgO}$ in the cement matrix decreases accordingly and the contact probability of $\mathrm{Mg}^{+}$and $\mathrm{SO}{ }^{-}$with $\mathrm{MgO}$ hydrated layer in magnesium sulfate solution is lower, which reduce the formation of the strength phase in the unit column and make the strength decline.(2) On the other hand, the concentration of the solution $(\mathrm{H})$ is constant, additional fly ash can reduce water-cement ratio(w/c), fly ash also has micro-aggregate effect on magnesium oxysulfate cement,and fine particles in hardened cement have certain filling effect ${ }^{[8]}$.These two functions are contradictory.
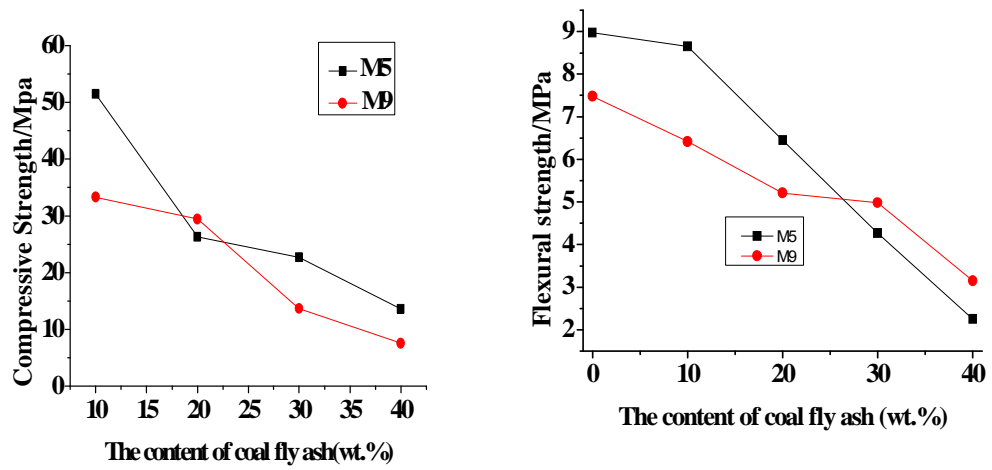

Fig 2 Effects of content of coal fly ash strength of magnesium oxysulfate cement on compressive and flexural strength

A similar water-cement ratio(w/c)should be maintained which is convenient for construction and keep the cement paste fluidity.Therefore, the effect of the dosage of fly ash on the $28 \mathrm{~d}$ strength of the cement paste with the same water-cement ratio (w/c) was investigated.The results show that with the increasing dosage of fly ash, the strength of the cement decreases linearly .

For example( $\mathrm{M}=5$ ), when the fly ash accounts for $40 \%$ (equivalent to $90 \%$ of the quality of LBM), the compressive and flexural strength are only $13.6 \mathrm{MPa}$ and $2.3 \mathrm{MPa}$.Compared to the cement paste without any fly ash, the strength decreases by $73.6 \%$ and $74.9 \%$ respectively. The reason is that the water-cement ratio(w/c) remains constant, with the increase of fly ash, more water is needed which makes $\mathrm{H}$ increase in cement paste and that can also reduce the content of strength phase in the cement matrix.Fig 3 presents that the addition of fly ash does not generate any hydrated magnesium silicate or mullite phase, because it is difficult to inspire the pozzolanic effect in the magnesium oxysulfate cement system of low alkalinity $(\mathrm{pH}=8.5 \sim 9.5)$. But when $\mathrm{M}=5$, the increasing dosage of fly ash makes the content of 5.1.7 phase reduce, which is adverse to the formation of 5.1.7 phase.

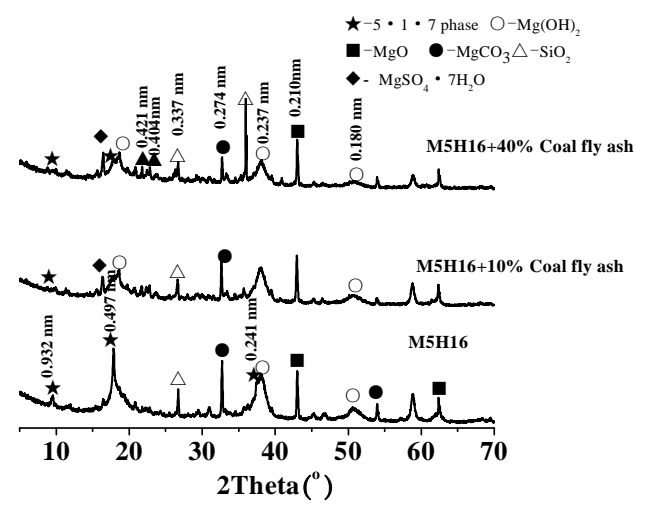

Fig. 3 Effets of coal fly ash on hydration products of magnesium oxysulfate cement 
Effect of slag on magnesium and magnesium cement

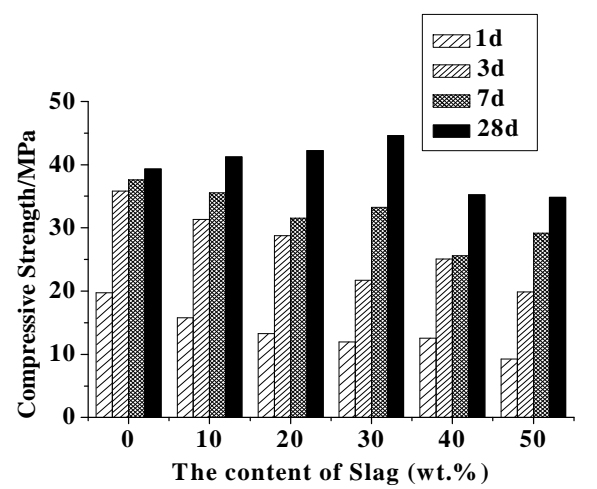

Fig 4 Effects of slag on compressive strength of magnesium oxysulfate cement $(\mathrm{W} / \mathrm{C}=0.45$ 、 a-MgO: $\mathrm{MgSO}_{4}: \mathrm{H}_{2} \mathrm{O}=8: 1: 20$ )

With the increase of slag, 28d compressive strength of magnesium oxysulfate cement increases first and then decreases.For example, when the dosage is $30 \%$, the highest compressive strength is 44.6MPa,increases by $13.42 \%$. While increasing the dosage of slag can decrease the strength of magnesium oxysulfate cement, the decline is not very obvious.Even when the slag content is $50 \%$, the compressive strength of the slag reduces by $11.3 \%$.In short, the addition of slag is adverse to he early strength of magnesium oxysulfate cement,but the decreasing rang of the late strength is smaller,compared with those mixed with fly ash.

Effect of silica fume on magnesium oxysulfate cement

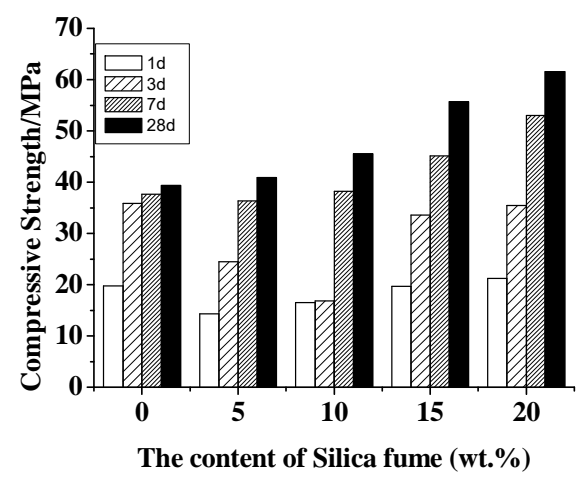

Fig 5 Effects of silca fume on compressive strength of magnesium oxysulfate cement(a-MgO:MgSO $\left.4: \mathrm{H}_{2} \mathrm{O}=8: 1: 20\right)$

It can be seen from Fig 5 that the effect of silica fume on the early compressive strength of magnesium oxysulphate cement first decreases and then increases. When the dosage of silica fume is $10 \%$, the strength of $3 \mathrm{~d}$ is the lowest, which is about $52.9 \%$, compared with that without silica fume.This may be due to the silica fume is fully filled in the gaps of the cement mortar., the mortar structure becomes more compact and uniform, and effectively improve the stress distribution of cement mortar which is useful for increasing the strength. When the dosage of silica fume is $20 \%$, the compressive strength of $28 \mathrm{~d}$ increases from $39.3 \mathrm{MPa}$ to $61.5 \mathrm{MPa}$, which increases by $56.4 \%$.Adding silica fume can be disadvantageous to the early strength of magnesium oxysulfate cement, but it can improve the later strength . 


\section{Conclusions}

Influences of mineral admixtures on the comrpessive strength of magnesium oxysulphate cement have been studied in this paper,results demonstrate that effects on compressive strength of magnesium oxysulphate cement by adding fly ash is related with the initial a-MgO/MgSO4. When $\mathrm{M}$ is low, the addition of fly ash will reduce the strength of cement. While $\mathrm{M}$ is high, the addition of appropriate amount of fly ash can improve the strength of oxysulphate cement.The strength of cement is significantly decreased by the addition of fly ash,with the constant water-cement ration(w/c). Although the addition of slag has a negative effect on the early strength of magnesium oxysulphate cement, it can be affected slightly.With the increasing addition of silica fume, the early strength of the magnesium oxysulphate cement decreases at first and then increases, and the later strength reduces obviously.

\section{Acknowledgements}

This study was supported by the National Natural Science Foundations of China (grants no .U1407104 ,no.214011209 and no.51662035 ),Natural Science Foundations of Qinghai Province (grants no .2015-ZJ-937Q and no.2015-ZJ-957Q) .

\section{References}

[1]. Beaudion, J. J., and Ramachandran, V. S., "Strength Development in Magnesium Oxysulfate Cement," Cement and Concrete Research, V. 8, No.1, 1977, pp. 103-112.

[2]. Newman, E. S., "Preparation and Heat of Formation of a Magnesium Oxysulfate," Journal of Research of the National Bureau of Standards, V. 68A, No. 6, 1964, pp. 645-650.

[3] Li Y, Yu H F ,heng L N,et al.Compressive strength of fly ash magnesium oxysulphate cement containing granite wastes [J] Constructure and Reaserch ,2003(33):1311-1317.

[4]Yu H F,Li ST,HE QY,Ding XQ,.Research on long-term strength and water-resistance of MgO-SF-FA-Mgcl2-H2O system cementitious materials[J]. Chin Ceramic Soc,2000,12(10):240.

[5]Li ZG,Ji ZS.Research progress on deformation an cracking of magnesium oxychloride cement products[J].B Chin Ceram Soc,2012,3(2)291-300.

[6] Dong JM, Yu HF, Zhang LM (2010) Study on experimental conditions of hydration methods of determining active magnesium oxide content [J].Salt Lake Res 18(1):38-41.

[7]Wen J, Yu HF, W CY, Li Y, D JM, Zh LN.Hydration kinetic and influencing parameters in hydration process of magnesium oxychloride cement [J]. J Chin Ceramic Soc,2013, 41(5):588-595.

[8]Jiang Ll, Chen YM, Yu K, Wei L, Chen SH, Sun YD,Han BW,W ML,Huang JN.Effect of fly ash on the compressive strength of magnesium oxychloride cement [J].B Chin Ceram Soc,2015,34(5):1427-1430. 